Editorial

Volume 1 Issue 2 - May 2016
J Anest \& Inten Care Med

Copyright (c) All rights are reserved by Amballur David John M.D

\title{
Focusing on Fundamentals
}

\author{
Amballur David John M.D* \\ Department of Anesthesiology and Critical Care Medicine, Johns Hopkins University School of Medicine, USA
}

Submission: May 7, 2016; Published: May 10, 2016

*Corresponding author: Amballur David John, Department of Anesthesiology and Critical Care Medicine, Johns Hopkins University School of Medicine, Baltimore, Maryland, USA, Email: ajohn1@jhmi.edu

\section{Introduction}

In a time of rapid knowledge expansion, technological innovation, emphasis on cost containment and improving efficiency in delivering medical care, it is easy to overlook the fundamentals of medicine. The sudden onset of new diseases, such as the Ebola virus which can cause rapid spread, panic, multisystem failure, and death or the Zika virus which is spread by an abundant common factor the mosquito, and which can cause catastrophic developmental anomalies to pregnant women resulting in children who will bear the consequences of these defects for a life time; emphasizes the importance of acquiring and spreading information, quickly.Despite advances in drug development the presence of multi-resistant organisms continues to grow at concomitant rapid pace. With each advancement in medicine the result and consequences also come to light and become more apparent. The need to address these issues help to spur the advance of knowledge and technology. Every effort to increase the rapid spread of information disperse knowledge contributes to the progress of the field of medicine.

The scope of medicine is enormous...from understanding the fundamentals of a disease process, to the development of solutions to combat the disease; and clinical implementation of the solutions. Each step in the process requires dedicated subspecialist with advanced and specific knowledge. Although each participant has their own technical and linguistic approach to their area of knowledge, it is by expressing their knowledge in a common forum that all participant are able to acquire an understanding of the work that is being done; and hasten their own inquiries and expand their own practice so that the progress of the work is rapidly dispersed and shared.

On a geographic scale the scope and practice of medicine is vast. Yet, in reality the purpose of medicine is about a patient. A patient is not an abstraction. This is an individual, a distinct sole, a human being. As a human being each individual has his or her unique, personal issues, environment, background, cares, worries, and composition. A person is not a disease, class, or category. A person is a human being. This is the fundamental basis of medicine. The essence of medicine is about an individual, a human being and is underscored by Hippocrates First and Most Fundamental Dictum of medicine; "First do no harm!"

According to the modern heath care industry or healthcare system...physician, scientists, nurses, assistants, aids, and students are providers who deliver a product to a consumer. This is wrong. It reflects a complete failure to understand the fundamental purposes of medicine.

Medicine is not a drug, a technology, a process, or an industry. The fundamental core of medicine is caring for an individual "a human being". This is why medicine transcends...war, race, religion, and social boundaries. It affects each of us; because, we are all, each of us sole, solitary, individual "a human being". 